\title{
Arsenic exposure from drinking water and dyspnoea risk in Araihazar, Bangladesh: a population-based study
}

\author{
Gene R. Pesola*,\#, Faruque Parvez ${ }^{\uparrow,+}$, Yu Chen ${ }^{\S}$, Alauddin Ahmed ${ }^{+}$, \\ Rabiul Hasan ${ }^{+}$and Habibul Ahsan ${ }^{\#,+, f}$
}

ABSTRACT: Bangladesh has high well water arsenic exposure. Chronic arsenic ingestion may result in diseases that manifest as dyspnoea, although information is sparse.

Baseline values were obtained from an arsenic study. Trained physicians ascertained data on dyspnoea among 11,746 subjects. Data were collected on demographic factors, including smoking, blood pressure and arsenic exposure. Logistic regression models estimated odds ratios and confidence intervals for the association between arsenic exposure and dyspnoea.

The adjusted odds of having dyspnoea was 1.32-fold (95\% Cl 1.15-1.52) greater in those exposed to high well water arsenic concentrations $\left(\geqslant 50 \mu \mathrm{g} \cdot \mathrm{L}^{-1}\right)$ compared with low-arsenicexposed nonsmokers $(p<0.01)$. A significant dose-response relationship was found for arsenic (as well as smoking) in relation to dyspnoea. In nonsmokers, the adjusted odds of having dyspnoea were 1.36, 1.96, 2.34 and 1.80-fold greater for arsenic concentrations of 7-38, 39-90, 91178 and $179-864 \mu \mathrm{g} \cdot \mathrm{L}^{-1}$, respectively, compared with the reference arsenic concentration of $<7 \mu \mathrm{g} \cdot \mathrm{L}^{-1}(\mathbf{p}<0.01$; Chi-squared test for trend).

Arsenic exposure through well water is associated with dyspnoea, independently of smoking status. This study suggests that mandated well water testing for arsenic with reduction in exposure may significantly reduce diseases that manifest as dyspnoea, usually cardiac or pulmonary.

KEYWORDS: Arsenicosis, dyspnoea dose-response, environmental dyspnoea

B angladesh is exposed to high well water concentrations of inorganic arsenic due to natural deposits underground $[1,2]$. The current World Health Organization (WHO) and US standards for acceptable arsenic content of drinking water is $<10 \mu \mathrm{g} \cdot \mathrm{L}^{-1}$ [2]. The Bangladesh standard is $<50 \mu \mathrm{g} \cdot \mathrm{L}^{-1}$ and it has been estimated that about one out of 100 subjects exposed to this elevated level in drinking water could die of liver, lung, kidney or bladder cancer over a lifetime [2]. A positive association between well water arsenic exposure and dyspnoea has been suggested in cross-sectional studies $[3,4]$. One large study compared the effects of arsenic levels in well water at $\geqslant 500 \mu \mathrm{g} \cdot \mathrm{L}^{-1}$ with $<50 \mu \mathrm{g} \cdot \mathrm{L}^{-1}$ and found age-adjusted prevalence odds ratios (PORs) of 23.2 (95\% CI 5.8-92.8) and 3.7 (1.3-10.6) for nonsmoking females and males, respectively, for presence of dyspnoea [3]. These high PORs occurred only in those with arsenic skin lesions [3]. A second study found nonsignificant PORs of $1.6(0.6-4.2)$ and $3.8(0.7-20.6)$ in subjects with arsenic-associated skin lesions versus no skin lesions for female and males, respectively, in nonsmoking subgroups [4]. The well water arsenic concentrations were described as $\geqslant 100 \mu \mathrm{g} \cdot \mathrm{L}^{-1}$ in $\geqslant 90 \%$ of those with skin lesions [4].

Bangladesh is eighth in the world in terms of total number of smokers $[5,6]$. Of the world's eight leading causes of death (heart disease, cerebrovascular disease, lower respiratory infections, chronic obstructive pulmonary disease (COPD), HIV/ AIDS, diarrhoeal disease, tuberculosis, and cancers of the trachea, bronchus and lung), smoking is a risk factor for all but HIV/AIDS and diarrhoeal diseases [5, 6]. Most of these smoking-related diseases can also present with dyspnoea.

The purpose of this investigation was to determine whether elevated well water arsenic exposure was associated with chronic dyspnoea, independently of smoking. This is a rare opportunity to determine whether or not chronic arsenic exposure causes dyspnoea. Detection of an arsenic-dyspnoea relationship would serve as further incentive to completely eliminate arsenic from well
AFFILIATIONS

*Division of Pulmonary and Critical Care Medicine, Dept of Medicine, Harlem Hospital, Columbia University,

\#Depts of Epidemiology,

"Environmental Health Sciences,

Mailman School of Public Health, Columbia University,

${ }^{\S}$ Dept of Environmental Medicine, NYU Langone Medical Center, New York, NY,

${ }^{f}$ Dept of Health Studies, Medicine, and Human Genetics and Cancer Research Center, University of Chicago, Chicago, IL, USA.

${ }^{+}$Columbia University Arsenic and Health Research Office in Bangladesh, Dhaka, Bangladesh.

CORRESPONDENCE

G.R. Pesola

Harlem Hospital/Columbia University Dept of Medicine

Section of Pulmonary Disease

MLK 12106

506 Lenox Ave

New York

NY 10037

USA

E-mail: grp4@columbia.edu

Received:

March 082011

Accepted after revision:

Oct 092011

First published online:

Nov 162011

European Respiratory Journal Print ISSN 0903-1936

Online ISSN 1399-3003 
water and reduce the Bangladesh arsenic water standard to that of the WHO.

\section{MATERIALS AND METHODS Data source and approvals}

Study subject baseline data were obtained from the cohort study "Health Effects of Arsenic Longitudinal Study" (HEALS) [7]. Study procedures were approved by the ethical committee of the Bangladesh Medical Research Council (Dhaka, Bangladesh) and institutional review boards of Columbia University (New York, NY, USA) and University of Chicago (Chicago, IL, USA).

\section{Subjects and demographics}

Baseline data were collected as previously described [7]. In brief, eligibility for HEALS included being aged $\geqslant 18$ yrs, being married (stability of residence), and having resided in Araihazar, Bangladesh for $\geqslant 5$ yrs.

After obtaining consent, a 45-min interview collected demographics including age, sex, body mass index (BMI), educational attainment (0-16 yrs), occupational history and smoking (past, present or never). Vital signs, including blood pressure, were measured, as were height and weight. A spot urine sample was collected and stored as described [7]. The baseline clinical examination included an assessment of arsenic-related skin lesions [7].

The outcome variable dyspnoea was determined by trained physicians asking the question "During the last 6 months, have you had dyspnoea?" Elicitation of the presence or absence of dyspnoea in this patient population has a reliability $>90 \%$ [8].

\section{Laboratory analysis}

Well water arsenic concentrations were analysed at the Geochemistry Research Laboratory of Columbia University [9] by graphite furnace atomic absorption (GFAA). The detection limit for GFAA was $5 \mu \mathrm{g} \cdot \mathrm{L}^{-1}$. Water samples with concentrations at the detection limit were re-analysed by inductively coupled plasmamass spectrometry with a detection limit of $0.1 \mu \mathrm{g} \cdot \mathrm{L}^{-1}[10]$.

The urinary arsenic concentration was measured by GFAA spectrometry [11]. Urinary creatinine was measured by a colorimetric diagnostics kit (Sigma, St Louis, MO, USA) and the total arsenic in urine (in $\mu \mathrm{g} \cdot \mathrm{L}^{-1}$ ) was divided by the urinary concentration of creatinine (in $\mathrm{g} \cdot \mathrm{L}^{-1}$ ) to obtain an adjusted concentration of arsenic (in $\mu \mathrm{g} \cdot \mathrm{g}^{-1}$ creatinine) [12].

\section{Statistical analysis}

The Pearson Chi-squared test was used to compare categorical data between sexes for BMI, smoking and arsenic concentrations, and for calculating well water arsenic concentrations by five groups from high to low, with dyspnoea as the outcome. The Chisquared test for trend (linear-by-linear association) was used to determine whether increasing cigarette consumption or increasing well water or urinary arsenic concentrations resulted in a significant increase in prevalence of dyspnoea. An unpaired t-test was conducted to compare ages between females and males. The Pearson correlation coefficient determined the correlation between water arsenic concentration and urinary arsenic excretion.

Unconditional logistic regression was used to estimate the odds ratio for dyspnoea. BMI was categorised into three groups (normal or reference BMI $18.50-24.99 \mathrm{~kg} \cdot \mathrm{m}^{-2}$, low BMI
$<18.50 \mathrm{~kg} \cdot \mathrm{m}^{-2}$ and high BMI $\geqslant 25 \mathrm{~kg} \cdot \mathrm{m}^{-2}$ ). Well water arsenic concentration was coded, with $\geqslant 50 \mu \mathrm{g} \cdot \mathrm{L}^{-1}$ as exposed and $<50 \mu \mathrm{g} \cdot \mathrm{L}^{-1}$ as the reference group, in all analyses except for dose-response analyses among the nonsmoker group, in which quintiles of well water arsenic concentration or urinary arsenic excretion were used. Continuous variables included age, educational level and systolic blood pressure. For a sensitivity analysis in nonsmokers, well water arsenic concentrations were also coded as $\geqslant 25, \geqslant 12.5$ and $\geqslant 6.25 \mu \mathrm{g} \cdot \mathrm{L}^{-1}$ versus other and subsequent adjusted odds ratios for dyspnoea obtained. A pvalue $<0.05$ was significant.

Biological interaction was evaluated between arsenic $\left(\geqslant 50 \mu \mathrm{g} \cdot \mathrm{L}^{-1}\right.$ versus other) and smoking using prevalence of dyspnoea by joint status of two exposures [13, 14]. Analyses were performed with SPSS 18 (SPSS Inc., Chicago, IL, USA).

\section{RESULTS \\ Descriptive data, arsenic skin lesion status and arsenic exposure data}

The overall mean \pm SD (range) population age was $37.1 \pm 10.1$ (17$75)$ yrs. For females and males the ages were 33.6 $\pm 8.9(18-61)$ yrs and $41.6 \pm 9.9(20-75)$ yrs, respectively $(\mathrm{p}<0.01)$.

Baseline distributions for demographic variables for sex, BMI, smoking status and well arsenic concentration are summarised in table 1 . The sex distributions for BMI are significantly different $(\mathrm{p}<0.01)$, with more females than males in the normal BMI category. The sex distributions for smoking status are also significantly different $(\mathrm{p}<0.01)$, with $62 \%$ of males being smokers compared with $3.7 \%$ of females.

Table 2 compares quintiles of well water arsenic exposure versus the dichotomous outcome variable, presence or absence of

\begin{tabular}{|c|c|c|c|c|}
\hline \multirow[t]{2}{*}{ TABLE 1} & \multicolumn{4}{|c|}{$\begin{array}{l}\text { Distribution of Health Effects of Arsenic } \\
\text { Longitudinal Study (HEALS) participants }\end{array}$} \\
\hline & & Total & Females & Males \\
\hline Subjects & & 11746 & 6704 & 5042 \\
\hline \multicolumn{5}{|l|}{$B M I^{* *} \mathbf{k g} \cdot \mathbf{m}^{-2}$} \\
\hline$<18.50$ & & 4555 (38.8) & $2333(34.8)$ & $2222(44.1)$ \\
\hline $18.50-24.99$ & & 6108 (52.0) & 3696 (55.1) & $2412(47.8)$ \\
\hline$>25.00$ & & 804 (6.8) & $515(7.7)$ & $289(5.7)$ \\
\hline Missing & & $279(2.4)$ & $160(2.4)$ & $119(2.4)$ \\
\hline \multicolumn{5}{|l|}{ Smoking** } \\
\hline Nonsmoker & & $7568(64.4)$ & $6282(93.7)$ & $1286(25.5)$ \\
\hline Ex-smoker & & $777(6.6)$ & $168(2.5)$ & 609 (12.1) \\
\hline Smoker & & $3390(28.9)$ & $247(3.7)$ & $3143(62.3)$ \\
\hline Missing & & $11(0.1)$ & 7 & 4 \\
\hline \multicolumn{5}{|c|}{ Baseline well arsenic $\mu \mathrm{g} \cdot \mathrm{L}^{-1}$} \\
\hline Quintile 1: & & 2325 (19.8) & $1318(19.7)$ & $1007(20.0)$ \\
\hline Quintile 2: 7 & $<39$ & $2354(20.0)$ & $1350(20.1)$ & $1004(19.9)$ \\
\hline Quintile 3: 3 & $-<91$ & 2333 (19.9) & $1347(20.1)$ & $986(19.6)$ \\
\hline Quintile 4: 9 & $-<179$ & $2382(20.3)$ & $1364(20.3)$ & $1018(20.2)$ \\
\hline Quintile 5: & 179 & 2352 (20.0) & 1325 (19.7) & $1027(20.4)$ \\
\hline
\end{tabular}

Data are presented as $n$ or $n(\%)$. BMI: body mass index. ${ }^{* *}: \mathrm{p}<0.01$ by Chisquared test for the sex distributions of $\mathrm{BMl}$ and smoking. 


\begin{tabular}{|c|c|c|c|}
\hline TABLE 2 & \multicolumn{3}{|c|}{$\begin{array}{l}\text { Logistic regression model in male and female } \\
\text { nonsmokers combined, comparing quintiles of } \\
\text { well water arsenic concentration with the } \\
\text { presence or absence of arsenic skin lesions }\end{array}$} \\
\hline \multicolumn{2}{|c|}{ Independent variables } & Adjusted OR (95\% Cl) & p-value \\
\hline \multicolumn{4}{|c|}{ Well arsenic quintile ${ }^{\#}$} \\
\hline \multicolumn{2}{|l|}{ 1: reference } & 1.00 & \\
\hline \multicolumn{2}{|l|}{2} & $1.80(1.02-3.16)$ & 0.043 \\
\hline \multicolumn{2}{|l|}{3} & $2.79(1.62-4.78)$ & $<0.001$ \\
\hline \multicolumn{2}{|l|}{4} & $3.09(1.82-5.23)$ & $<0.001$ \\
\hline \multicolumn{2}{|l|}{5} & $3.94(2.36-6.58)$ & $<0.001^{\star *}$ \\
\hline \multicolumn{2}{|l|}{ Age } & $1.05(1.03-1.06)$ & $<0.001$ \\
\hline \multicolumn{2}{|l|}{ Education } & $0.95(0.92-0.99)$ & 0.007 \\
\hline \multicolumn{2}{|l|}{ Sex $\operatorname{Se}^{\pi}$} & $0.27(0.20-0.35)$ & $<0.001$ \\
\hline \multicolumn{2}{|l|}{ Systolic BP } & $1.01(0.99-1.01)$ & 0.167 \\
\hline \multicolumn{4}{|l|}{ BMI group ${ }^{+}$} \\
\hline \multicolumn{2}{|l|}{1} & $1.41(1.07-1.87)$ & 0.016 \\
\hline \multicolumn{2}{|l|}{2} & $0.66(0.37-1.19)$ & 0.170 \\
\hline
\end{tabular}

BP: blood pressure; BMI: body mass index. ${ }^{\#}$ : the reference well water arsenic concentration was $<7 \mu \mathrm{g} \cdot \mathrm{L}^{-1}$, with quintiles as described in table $1 ;{ }^{\circ}$ : the reference for sex was male; ${ }^{+}$: BMl categorised as low $\left(<18.5 \mathrm{~kg} \cdot \mathrm{m}^{-2}\right.$; group 1) and high ( $\geqslant 25 \mathrm{~kg} \cdot \mathrm{m}^{-2}$; group 2). ${ }^{\star *}: \mathrm{p}<0.01$ by Chi-squared test for trend.

arsenic-associated skin lesions. There is a clear dose-response between increasing well water arsenic concentrations and the presence of skin lesions. Using the presence of arsenic skin lesions as the exposure marker of interest revealed a 2.2-fold greater odds of dyspnoea for individuals with arsenic-related skin lesions compared with those without, after adjustment (table 3). This analysis was done in nonsmokers only. Similar results were found when including all subjects, females only and males only (data not shown).

\begin{tabular}{llc} 
TABLE 3 & $\begin{array}{l}\text { Logistic regression model in male and female } \\
\text { nonsmokers combined, comparing arsenic skin } \\
\text { lesions with the primary outcome variable of the } \\
\text { presence or absence of dyspnoea }\end{array}$ \\
$\begin{array}{l}\text { Independent variables } \\
\text { Adjusted OR (95\% Cl) }\end{array}$ & p-value \\
\hline Skin lesions & & \\
$\quad$ No: reference & 1.00 & \\
Yes & $2.24(1.52-3.30)$ & $<0.001$ \\
Age & $1.03(1.02-1.04)$ & $<0.001$ \\
Education & $0.96(0.94-0.99)$ & 0.004 \\
Sex & $1.77(1.32-2.36)$ & $<0.001$ \\
Systolic BP & $1.00(0.99-1.01)$ & 0.385 \\
BMI group & & 0.079 \\
1 & $1.19(0.98-1.45)$ & 0.148 \\
2 & $1.27(0.92-1.76)$ & \\
\hline
\end{tabular}

BP: blood pressure; BMI: body mass index. Similar results were obtained when females and males were analysed separately. ${ }^{*}$ : the reference for sex was male; $\because$ : BMl categorised as low $\left(<18.5 \mathrm{~kg} \cdot \mathrm{m}^{-2}\right.$; group 1) and high $\left(\geqslant 25 \mathrm{~kg} \cdot \mathrm{m}^{-2}\right.$; group 2).
The Pearson correlation coefficient between water arsenic concentration and urinary arsenic concentration was 0.556 $(\mathrm{p}<0.001)$.

Arsenic as primary exposure variable in the total population Table 4 is a summary of the adjusted odds ratios for dyspnoea in relation to well water arsenic exposure and smoking status. Both arsenic and smoking, in any of the three smoking categories, were independent and significantly related to dyspnoea. Age and education were directly and inversely associated with increased dyspnoea, respectively.

An analysis eliminating ex-smokers was performed to determine whether there was a dose-response relationship between levels of smoking and dyspnoea $(n=10,958)$. The crude odds ratio for both cigarette groups was significant, with similar odds ratios for females and males combined before adjustment (table 5). No dose response was seen. However, there was a significant adjusted dose response for females and males. Separating groups by sex revealed only 15 females who smoked $>10$ cigarettes per day; therefore, females could not be analysed by dose response. For males, the crude and adjusted OR Chi-squared test for trend were significant, implying a dose-response relationship between cigarette smoking and dyspnoea.

Biological interaction between arsenic and smoking was not found $[13,14]$. In particular, on evaluating all subjects, in the low arsenic nonsmoking group (reference), the prevalence of dyspnoea was $5.4 \%$. The high arsenic $\left(\geqslant 50 \mu \mathrm{g} \cdot \mathrm{L}^{-1}\right)$ nonsmoking group had a prevalence of dyspnoea of $8.24 \%$. The low arsenic smoking group had a prevalence of dyspnoea of $8.73 \%$. Finally, the high arsenic smoking group had a prevalence of dyspnoea of $8.84 \%$. Biological interaction, or interaction on the additive scale, would only be present if the actual combined prevalence exceeded the theoretical prevalence.

Biological interaction was also evaluated for all males only, all females only, male smokers only (excluding ex-smokers), female smokers only (excluding ex-smokers), male ex-smokers (excluding active smokers) and female ex-smokers (excluding active smokers). No interaction was found.

\section{Arsenic as primary exposure variable, excluding smokers}

Table 6 was created by eliminating smokers. The primary exposure variable is elevated well water arsenic concentration $\left(\geqslant 50 \mu \mathrm{g} \cdot \mathrm{L}^{-1}\right)$ versus reference $\left(<50 \mu \mathrm{g} \cdot \mathrm{L}^{-1}\right)$. Compared with the crude odds ratio, table 6 reveals similar elevated adjusted odd ratios among never-smokers for all subjects, females and males. After exclusion of smokers, the association between arsenic and dyspnoea increased, as seen by increased odds ratio. The odds ratio for dyspnoea was greater for males than females. The sensitivity analysis using well water arsenic cut-off values of $\geqslant 25, \geqslant 12.5$ and $\geqslant 6.25 \mu \mathrm{g} \cdot \mathrm{L}^{-1}$ versus other, revealed adjusted odds ratios of 1.62 (95\% CI 1.31-2.01), 1.81 (95\% CI 1.42-2.31) and 1.80 (95\% CI 1.37-2.37), respectively. These results were robust and even higher than the odds ratio of 1.56 (95\% CI 1.29-1.88) seen in table 6 using the well water arsenic cut-off of $\geqslant 50 \mu \mathrm{g} \cdot \mathrm{L}^{-1}$.

Table 7 shows analysis where arsenic categories were divided into quintiles. The reference or lowest quintile was a well water arsenic concentration of $<7 \mu \mathrm{g} \cdot \mathrm{L}^{-1}$. The other quintiles were $7-$ $<39,39-<91,91-<179$ and $179-864 \mu \mathrm{g} \cdot \mathrm{L}^{-1}$. A dose response was seen going from quintiles 1 through 4 , with odds ratio 
TABLE 4 Logistic regression model with the primary exposure variable of well water arsenic exposure, controlling for smoking category, with the outcome variable of interest of the presence or absence of dyspnoea

\begin{tabular}{|c|c|c|c|c|c|c|}
\hline Independent variables & \multicolumn{2}{|c|}{ Smokers plus ex-smokers ${ }^{\#}$} & \multicolumn{2}{|c|}{ Current smokers ${ }^{\pi}$} & \multicolumn{2}{|c|}{ Ex-smokers $^{+}$} \\
\hline Reference & 1.00 & & 1.00 & & 1.00 & \\
\hline High & $1.32(1.15-1.52)$ & $<0.001$ & $1.33(1.14-1.54)$ & $<0.001$ & $1.51(1.27-1.79)$ & $<0.001$ \\
\hline \multicolumn{7}{|l|}{ Smoking $f$} \\
\hline Current smokers & & & $1.38(1.09-1.75)$ & 0.008 & & \\
\hline Ex-smokers & & & & & $1.64(1.22-2.20)$ & $<0.001$ \\
\hline Age & $1.03(1.02-1.04)$ & $<0.001$ & $1.03(1.02-1.04)$ & $<0.001$ & $1.03(1.02-1.04)$ & $<0.001$ \\
\hline Education & $0.96(0.92-0.98)$ & $<0.001$ & $0.96(0.94-0.98)$ & $<0.001$ & $0.96(0.94-0.99)$ & 0.002 \\
\hline Sex\# & $1.58(1.28-1.95)$ & $<0.001$ & $1.56(1.24-1.96)$ & $<0.001$ & $1.60(1.24-2.05)$ & $<0.001$ \\
\hline Systolic BP & $1.00(0.99-1.00)$ & 0.488 & $1.00(0.99-1.00)$ & $<0.692$ & $1.00(0.99-1.01)$ & 0.648 \\
\hline
\end{tabular}

increasing from 1.00 up to 2.17. The fifth quintile had an odds ratio of 1.84 , still significant but smaller than quintiles 3 and 4 . The adjusted odds ratios were no different from the crude values (table 7). The Pearson Chi-squared test for well water arsenic concentrations in five groups in relation to the dichotomous outcome variable dyspnoea was significant at $\mathrm{p}<0.01$ (four degrees of freedom, Chi-squared 31.4). The Chi-squared test for trend for increasing odds ratio as well water arsenic concentration increased was significant at $\mathrm{p}<0.01$ (one degree of freedom, Chisquared 21.4).

TABLE 5 Logistic regression model excluding ex-smokers, comparing smoking dose-response with dyspnoea

\begin{tabular}{|c|c|c|c|c|c|c|}
\hline \multirow[t]{2}{*}{ Independent variables } & \multirow{2}{*}{$\begin{array}{c}\text { Crude OR } \\
(95 \% \mathrm{Cl})\end{array}$} & \multirow[t]{2}{*}{ p-value } & \multicolumn{2}{|c|}{ Females and males } & \multicolumn{2}{|c|}{ Males only\# } \\
\hline & & & $\begin{array}{c}\text { Adjusted OR } \\
(95 \% \mathrm{Cl})\end{array}$ & p-value & $\begin{array}{c}\text { Adjusted OR } \\
(95 \% \mathrm{Cl})\end{array}$ & $\mathrm{p}$-value \\
\hline \multicolumn{7}{|l|}{ Females and males } \\
\hline Nonsmokers & 1.00 & & 1.00 & & & \\
\hline \multicolumn{7}{|l|}{ Males only } \\
\hline Nonsmokers & 1.00 & & & & 1.00 & \\
\hline$\leqslant 10$ cigarettes per day & $1.75(1.29-2.38)$ & $<0.001$ & & & $1.46(1.05-2.03)$ & 0.021 \\
\hline$>10$ cigarettes per day & $1.85(1.34-2.54)$ & $<0.001^{\star \star}$ & & & $1.48(1.06-2.08)$ & $0.022^{* *}$ \\
\hline Age & & & $1.03(1.02-1.04)$ & $<0.001$ & $1.03(1.02-1.04)$ & $<0.001$ \\
\hline Education & & & $0.96(0.94-0.98)$ & $<0.001$ & $0.96(0.93-0.99)$ & 0.014 \\
\hline \multicolumn{7}{|l|}{ BMI group ${ }^{+}$} \\
\hline 1 & & & $1.13(0.96-1.32)$ & 0.138 & $1.22(0.95-1.57)$ & 0.116 \\
\hline 2 & & & $1.42(1.07-1.88)$ & 0.016 & $2.10(1.30-3.39)$ & 0.002 \\
\hline
\end{tabular}

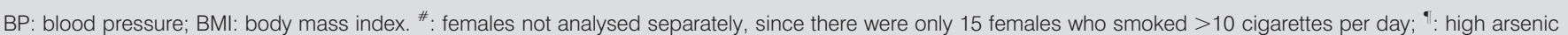
was $\geqslant 50 \mu \mathrm{g} \cdot \mathrm{L}^{-1} ;{ }^{+}$: BMl categorised as low $\left(<18.5 \mathrm{~kg} \cdot \mathrm{m}^{-2} ;\right.$ group 1) and high $\left(\geqslant 25 \mathrm{~kg} \cdot \mathrm{m}^{-2}\right.$; group 2). ${ }^{* *}: \mathrm{p}<0.01$ by Chi-squared test for trend. 


\begin{tabular}{|c|c|c|c|c|c|c|c|c|}
\hline \multirow[t]{2}{*}{ Independent variables } & \multirow{2}{*}{$\begin{array}{l}\text { Crude OR } \\
(95 \% \mathrm{Cl})\end{array}$} & \multirow[t]{2}{*}{$p$-value } & \multicolumn{2}{|c|}{ Females and males } & \multicolumn{2}{|c|}{ Females only } & \multicolumn{2}{|c|}{ Males only } \\
\hline & & & $\begin{array}{c}\text { Adjusted OR } \\
(95 \% \mathrm{Cl})\end{array}$ & p-value & $\begin{array}{c}\text { Adjusted OR } \\
(95 \% \mathrm{Cl})\end{array}$ & p-value & $\begin{array}{c}\text { Adjusted OR } \\
(95 \% \mathrm{Cl})\end{array}$ & $p$-value \\
\hline Males & $2.01(1.15-3.52)$ & 0.015 & & & & & & \\
\hline \multicolumn{9}{|l|}{ Well arsenic ${ }^{\#}$} \\
\hline Reference & 1.00 & & 1.00 & & 1.00 & & 1.00 & \\
\hline High & & & $1.56(1.29-1.88)$ & $<0.001$ & $1.51(1.23-1.84)$ & $<0.001$ & $2.00(1.14-3.52)$ & 0.016 \\
\hline Age & & & $1.03(1.02-1.04)$ & $<0.001$ & $1.03(1.02-1.05)$ & $<0.001$ & $1.03(1.00-1.05)$ & 0.050 \\
\hline 1 & & & $1.20(0.98-1.46)$ & 0.071 & $1.15(0.93-1.42)$ & 0.197 & $1.67(0.94-3.00)$ & 0.083 \\
\hline 2 & & & $1.28(0.92-1.77)$ & 0.139 & $1.19(0.83-1.70)$ & 0.350 & $1.96(0.88-4.36)$ & 0.099 \\
\hline
\end{tabular}

BP: blood pressure; BMI: body mass index. ${ }^{\#}$ : the reference well water arsenic concentration was $<50 \mu \mathrm{g} \cdot \mathrm{L}^{-1}$, with high arsenic being $\geqslant 50 \mu \mathrm{g} \cdot \mathrm{L}^{-1}$; ${ }^{\bullet}: \mathrm{BMI}$ categorised as low $\left(<18.5 \mathrm{~kg} \cdot \mathrm{m}^{-2} ;\right.$ group 1) and high $\left(\geqslant 25 \mathrm{~kg} \cdot \mathrm{m}^{-2} ;\right.$ group 2).

The quintiles of urinary arsenic excretion per gram of creatinine in relation to dyspnoea were also analysed (table 8). Both the crude (not shown) and adjusted values resulted in a significant dose response of increasing urinary arsenic

\begin{tabular}{|c|c|c|c|c|}
\hline \multirow{2}{*}{$\begin{array}{l}\text { TABLE } 7 \\
\text { Independent } \\
\text { variables }\end{array}$} & \multicolumn{4}{|c|}{$\begin{array}{l}\text { Logistic regression dose-response model in } \\
\text { nonsmokers, with the primary exposure variable } \\
\text { of well water arsenic and the outcome variable of } \\
\text { interest of the presence or absence of dyspnoea }\end{array}$} \\
\hline & $\begin{array}{c}\text { Crude OR } \\
(95 \% \mathrm{Cl})\end{array}$ & $p$-value & $\begin{array}{c}\text { Adjusted OR } \\
(95 \% \mathrm{Cl})\end{array}$ & $p$-value \\
\hline \multicolumn{5}{|l|}{$\begin{array}{l}\text { Well arsenic } \\
\text { quintile }^{\#}\end{array}$} \\
\hline 1: reference & 1.00 & & 1.00 & \\
\hline 2 & $1.39(0.99-1.93)$ & 0.052 & $1.36(0.97-1.90)$ & 0.074 \\
\hline 3 & $1.97(1.44-2.70)$ & $<0.001$ & $1.96(1.43-2.70)$ & $<0.001$ \\
\hline 4 & $2.17(1.59-2.95)$ & $<0.001$ & $2.14(1.56-2.92)$ & $<0.001$ \\
\hline 5 & $1.84(1.34-2.53)$ & $<0.001^{\star *}$ & $1.80(1.31-2.49)$ & $<0.001^{* *}$ \\
\hline Age & & & $1.03(1.02-1.04)$ & $<0.001$ \\
\hline Education & & & $0.96(0.94-0.99)$ & 0.004 \\
\hline Sex & & & $1.65(1.24-2.19)$ & 0.001 \\
\hline Systolic BP & & & $1.00(0.99-1.01)$ & 0.323 \\
\hline \multicolumn{5}{|l|}{ BMI group $\pi$} \\
\hline 1 & & & $1.21(0.99-1.47)$ & 0.064 \\
\hline 2 & & & $1.29(0.93-1.79)$ & 0.122 \\
\hline
\end{tabular}

excretion in relation to dyspnoea, as seen with well water arsenic. A similar analysis (data not shown) using urinary excretion of arsenic without adjustment for creatinine also found a significant Chi-squared test for trend dose response $(\mathrm{p}<0.01)$.

\section{DISCUSSION}

High baseline well water arsenic exposure was a significant risk factor for dyspnoea, adjusted for smoking (table 4). This arsenic-dyspnoea association was strong for all three smoking subgroups (table 4). In order to eliminate smoking effects, a separate analysis using only nonsmokers was carried out

\begin{tabular}{|c|c|c|c|}
\hline TABLE 8 & \multicolumn{3}{|c|}{$\begin{array}{l}\text { Logistic regression dose-response model in } \\
\text { nonsmokers, with the primary exposure variable } \\
\text { of urinary arsenic excretion and the outcome } \\
\text { variable of interest of the presence or absence of } \\
\text { dyspnoea }\end{array}$} \\
\hline \multicolumn{2}{|c|}{ Independent variables } & OR $(95 \% \mathrm{Cl})$ & $\mathrm{p}$-value \\
\hline \multicolumn{4}{|c|}{ Urinary arsenic quintile ${ }^{\#}$} \\
\hline \multicolumn{2}{|c|}{ 1: reference } & 1.00 & \\
\hline \multicolumn{2}{|l|}{2} & $1.37(0.97-1.92)$ & 0.073 \\
\hline \multicolumn{2}{|l|}{3} & $1.92(1.38-2.65)$ & $<0.001$ \\
\hline \multicolumn{2}{|l|}{4} & $1.94(1.41-2.68)$ & $<0.001$ \\
\hline \multicolumn{2}{|l|}{5} & $1.87(1.36-2.58)$ & $<0.001^{* *}$ \\
\hline
\end{tabular}

All data were adjusted for age, education, body mass index, systolic blood pressure and sex. ${ }^{*}$ : equal quintiles of urinary arsenic excretion (in $\mu \mathrm{g} \cdot \mathrm{L}^{-1}$ ) divided by the urinary concentration of creatinine (in $\mathrm{g} \cdot \mathrm{L}^{-1}$ ), resulting in an adjusted concentration of arsenic (in $\mu \mathrm{g} \cdot \mathrm{g}^{-1}$ creatinine). ${ }^{* *}: \mathrm{p}<0.01$ by Chisquared test for trend. 
(tables 6 and 7). An arsenic dose-response curve revealed an increased prevalence of dyspnoea with increasing well water arsenic concentrations using $<7 \mu \mathrm{g} \cdot \mathrm{L}^{-1}$ as reference (table 7 ). The odds ratio for the presence of dyspnoea increased from the reference to the second quintile. This result could argue for reducing the current Bangladesh arsenic water standard to at least the world standard of $<10 \mu \mathrm{g} \cdot \mathrm{L}^{-1}$ or lower, i.e. to levels $<7 \mu \mathrm{g} \cdot \mathrm{L}^{-1}$.

The positive association between arsenic exposure and respiratory symptoms has been suggested in three cross sectional studies that included only nonsmokers. A small study found a nonsignificant increase in the crude POR with either chronic bronchitis or chronic cough when the reference well water arsenic concentration was $<50 \mu \mathrm{g} \cdot \mathrm{L}^{-1}$. The highest POR was $2.7(95 \% \mathrm{CI}$ 0.3-16.9) [15]. A second study compared the age adjusted POR for those exposed to a reference arsenic concentration of $<50 \mu \mathrm{g} \cdot \mathrm{L}^{-1}$ versus those exposed to levels $\geqslant 500 \mu \mathrm{g} \cdot \mathrm{L}^{-1}$ [3]. For females, the POR for cough and dyspnoea were 7.8 (95\% CI 3.1-19.5) and 23.2 (95\% CI 5.8-92.8), respectively. For males, the same POR values were 5.0 (95\% CI 2.6-9.9) and 3.7 (95\% CI 1.3-10.6), respectively. These high POR were only present in those with skin lesions and were reduced but suggestive in all females and males [3]. A third study, using reference well water arsenic concentrations of $<50 \mu \mathrm{g} \cdot \mathrm{L}^{-1}$, found that $63 \%$ of individuals exposed to high well water arsenic concentrations $\left(67-875 \mu \mathrm{g} \cdot \mathrm{L}^{-1}\right)$ had pulmonary effects including cough, bronchitis and dyspnoea [16]. The comparison had only $7 \%$ of these effects [16]. A fourth small study of smokers and nonsmokers with well water arsenic concentrations less than $500 \mu \mathrm{g} \cdot \mathrm{L}^{-1}$ compared subjects with arsenic skin lesions (high exposure) versus those without arsenic skin lesions (lower exposure). The nonsmoking group revealed increased POR for dyspnoea, chronic cough and chronic bronchitis in both males and females of values around 2, albeit no statistically significant values were obtained [4].

Lung function testing has been evaluated in subjects with chronic arsenic ingestion in at least three studies $[4,17,18]$. These studies suggest a predominantly obstructive picture secondary to well water arsenic ingestion.

Two studies have looked specifically at whether or not there is an increase in bronchiectasis in subjects exposed to chronically elevated well water arsenic concentrations from 400 to $1,000 \mu \mathrm{g} \cdot \mathrm{L}^{-1}[19,20]$. The adjusted odds ratio or standardised rates ranged from 10 to $46[19,20]$. Both studies suggest that arsenic, which is ingested orally, causes bronchiectasis.

Dyspnoea was used as a proxy for diseases that manifest as shortness of breath, generally cardiac or pulmonary $85 \%$ of the time $[21,22]$. However, three studies have suggested a reduction in lung function that is obstructive in nature in subjects exposed to elevated water arsenic concentrations [4, 17, 18]. Dyspnoea tends to occur with COPD when the forced expiratory volume in $1 \mathrm{~s}$ is reduced to $50 \%$ of normal [23]. Therefore, one of the mechanisms of dyspnoea with arsenic exposure might be the development of COPD secondary to arsenic. In addition, lung cancer secondary to arsenic would undoubtedly present with dyspnoea [24-26]. Also, arsenic is associated with bronchiectasis $[19,20]$, a cause of dyspnoea.

Dyspnoea could also occur in subjects who develop cardiovascular disease secondary to arsenic exposure. Two studies have revealed a dose-response relationship between well water arsenic and heart disease [27, 28]. A third Chilean study found myocardial infarction mortality rate ratios of 1.48 (95\% CI 1.37$1.59)$ and 1.26 (95\% CI 1.14-1.40) for males and females, respectively, during a period of excessive arsenic exposure [29]. In Wisconsin, using well water arsenic concentration of $<2$ versus $>10 \mu \mathrm{g} \cdot \mathrm{L}^{-1}$, an increase in heart attacks and coronary bypass surgery were found with odds ratios of 2.08 (95\% CI 1.10-4.31) and 2.34 (95\% CI 1.12-4.90), respectively [30]. Finally, using a well water arsenic concentration $<1$ versus $>10 \mu \mathrm{g} \cdot \mathrm{L}^{-1}$ found mortality rates of 1.10 (95\% CI 1.08-1.12) and 1.18 (95\% CI 1.15-1.22) for cardiovascular and coronary heart disease, respectively [31]. Therefore, chronic arsenic exposure in drinking water predisposes to heart and lung disease, the two common causes of dyspnoea. Thus, our finding of a dose-response relationship between arsenic exposure and dyspnoea is biologically plausible.

It should be noted that the highest well water concentration of arsenic partially reverses the dose-response trend seen (table 7). The trend still maintained statistical significance probably related to a still very high odds ratio relative and close to the previous odds ratio. This finding could be related to random error, since the case number was limited in the highest level of arsenic exposure. A possible explanation for the finding, if real, is increased mortality at high arsenic exposure levels resulting in a reduced prevalence. Another possibility is a plateau in arsenic toxicity at a certain elevated level, although this would seem to be less likely from a biological point of view, since arsenic is a very toxic metal in humans. A third possibility is that the sickest subjects at baseline (many of whom may have had dyspnoea) with the highest arsenic exposure level may have declined to participate in the study. This selection bias out of the study might have resulted in a slight but spurious reversal of the dose response.

Smoking was also strongly associated with dyspnoea (table 4) with an adjusted dose-response relationship between cigarettes smoked and dyspnoea in males (table 5). Since dyspnoea is associated with an increase in mortality over time [32-36], smoking is clearly a risk factor for mortality in Bangladesh. All things considered, the smoking-dyspnoea relationship found is internally consistent with what is known about smoking and the diseases and deaths it causes $[5,6]$.

Study strengths include using the baseline arsenic water concentrations of tube wells before they were capped [37] due to high arsenic levels (to protect the residents from arsenic). Another strength was finding a very strong dose-response relationship between well water arsenic concentrations and the presence of arsenic-associated skin lesions (table 2); a finding previously demonstrated with cumulative and time-weighted well water arsenic exposures [38]. Arsenic skin lesions tend to occur 10-23 yrs after chronic arsenic exposure [39]. This finding further validates that well water arsenic exposure as used in this study was a good measure of long-term arsenic exposure in humans. A further strength was finding 2.4-fold (95\% CI 1.523.30) greater presence of dyspnoea in individuals with arsenicassociated skin lesions relative to those without skin lesions. This is additional evidence that chronic arsenic exposure is a risk factor for developing dyspnoea. Another main strength is that $86 \%$ of study participants used one index well exclusively, making well water arsenic concentrations a good index of 
exposure [38]. Other study strengths are a very large sample size, data acquisition by trained physician interviewers, individual measurement of exposure, the presence of a significant correlation between well water arsenic concentration and individual urine arsenic concentration (urinary arsenic at baseline was a measure of internal dose of continuing long-term exposure), which validates that the well water arsenic concentrations are the source of exposure, biological plausibility of both arsenic and smoking as aetiological causes of diseases that may result in dyspnoea, and the finding of a dose-response relationship with both well water arsenic concentrations and urinary arsenic excretion and dyspnoea. In addition, the ability to eliminate smoking from arsenic exposure with an increase in the arsenicdyspnoea association further strengthens the concept that chronic well water arsenic exposure results in dyspnoea. Furthermore, the ability to find an intuitively logical dose-response relationship with smoking and dyspnoea (table 5) serves as an internal standard validating that this arsenic database was collected correctly for other findings. Finally, despite the inability to exactly quantify individual arsenic exposure, a dose response with two different measures of arsenic exposure and dyspnoea was still present.

A study weakness is that dyspnoea signifies disease but explicit diseases were not determined due to the nature of collecting baseline data for cohort studies. Due to the cross-sectional nature, the temporal sequence of the exposure-outcome relationship could not be determined for either exposure, arsenic or smoking. However, since tube wells were placed in the late 1970s and 1980s and this study collected data 20 yrs later, an argument could be made that arsenic exposure preceded dyspnoea [2]. Finally, since the study is not randomised, it is possible that unknown confounders resulted in the findings.

We conclude that both arsenic and smoking have strong and independent associations with the symptom of chronic dyspnoea in Bangladesh. This is the only study to find a dose-response relationship with both exposures and dyspnoea. The arsenic findings are novel. Only one other study has found a significant association between arsenic water exposure and dyspnoea; a tentative dose-response was suggested but limited by small numbers [3]. The current study, due to larger size, is the first to demonstrate a clear dose-response relationship with arsenic water exposure and dyspnoea. In addition, there was a strong association with arsenic skin lesions and dyspnoea and a dose response with arsenic urinary concentrations and dyspnoea, both never before demonstrated with dyspnoea and both associations further validating the water exposure data. The smoking findings, conversely, are not unexpected; albeit never reported before as a dose response with dyspnoea. This suggests, if exposures are causal, that elimination of both would result in a marked reduction in the diseases that generally result in dyspnoea, usually cardiac and lung [21, 22]. This study adds to the list of arsenic-related diseases being detected in Bangladesh and worldwide $[5,6,19,20,24-31,39,40]$.

\section{SUPPORT STATEMENT}

This work was supported by National Institutes of Health (Bethesda, MD, USA) grants P42ES10349, R01CA107431 and R01CA102484.

\section{STATEMENT OF INTEREST}

None declared.

\section{ACKNOWLEDGEMENTS}

Presented in part in abstract form at the 2011 American Thoracic Society meeting (Denver, CO, USA). We dedicate this manuscript to the memory of Alvin S. Teirstein, previous section chief of pulmonary disease, Mt Sinai Hospital, New York, NY, USA.

\section{REFERENCES}

1 Chowdhury UK, Biswas BK, Chowdhury TR, et al. Groundwater arsenic contamination in Bangladesh and West Bengal, India. Environ Health Perspect 2000; 108: 393-397.

2 Smith AH, Lingas EO, Rahman M. Contamination of drinkingwater by arsenic in Bangladesh: a public health emergency. Bull World Health Org 2000; 78: 1093-1103.

3 Guha Mazumder DN, Haque R, Ghosh N, et al. Arsenic in drinking water and the prevalence of respiratory effects in West Bengal, India. Int J Epidemiol 2000; 29: 1047-1052.

4 von Ehrenstein OS, Guha Mazumder DN, Yuan Y, et al. Decrements in lung function related to arsenic in drinking water in West Bengal, India. Am J Epidemiol 2005; 162: 533-541.

5 Jha P. Avoidable global cancer deaths and total deaths from smoking. Nat Rev Cancer 2009; 9: 655-664.

6 World Health Organization. MOPOWER: A Policy Package to Reverse the Tobacco Epidemic. Geneva, World Health Organization, 2008.

7 Ahsan H, Chen Y, Parvez F, et al. Health effects of arsenic longitudinal study (HEALS): description of a multidisciplinary epidemiologic investigation. J Espo Sci Environ Epidem 2006; 16: 191-205.

8 Pesola GR, Parvez F, Jasmin S, et al. Dyspnea reproducibility in a rural Bangladesh population. Clin Respir J 2009; 3: 222-228.

9 van Geen A, Zheng Y, Versteeg $R$, et al. Spatial variability of arsenic in 6000 tube wells in a $25 \mathrm{~km}^{2}$ area of Bangladesh. Water Resour Res 2003; 39: 1140.

10 Cheng Z, Zheng Y, Mortlock R, et al. Rapid multi-element analysis of groundwater by high-resolution inductively coupled plasma mass spectrometry. Anal Bioanal Chem 2004; 379: 512-518.

11 Nixon DE, Mussmann GV, Eckdahl SJ, et al. Total arsenic in urine: palladium-persulfate vs nickel as a matrix modifier for graphite furnace atomic absorption spectrophotometry. Clin Chem 1991; 37: 1375-1379.

12 Nermell B, Lindberg AL, Rahman M, et al. Urinary arsenic concentration adjustment factors and malnutrition. Environ Res 2008; 106: 212-218.

13 Rothman KJ. Epidemiology. An Introduction. New York, Oxford University Press, 2002.

14 Andersson T, Alfredsson L, Kallberg H, et al. Calculating measures of biologic interaction. Eur J Epidem 2005; 20: 575-579.

15 Milton AH, Rahman M. Respiratory effects and arsenic contaminated well water in Bangladesh. Int J Environ Health Res 2002; 12: 175-179.

16 Islam LN, Nabi AHMN, Rahman MM, et al. Association of respiratory complications and elevated serum immunoglobulins with drinking water arsenic toxicity in human. J Environ Sci Health 2007; 42: 1807-1814.

17 De BK, Majumdar D, Sen S, et al. Pulmonary involvement in chronic arsenic poisoning from drinking contaminated groundwater. J Association Physicians India 2004; 52: 395-400.

18 Parvez F, Chen Y, Brandt-Rauf PW, et al. Nonmalignant respiratory effects of chronic arsenic exposure from drinking water among never-smokers in Bangladesh. Environ Health Perspect 2008; 116: 190-195.

19 Guha Mazumder DN, Steinmaus C, Bhattacharya P, et al. Bronchiectasis in persons with skin lesions resulting from arsenic in drinking water. Epidemiology 2005; 16: 760-765. 
20 Smith AH, Marshall G, Yuan Y, et al. Increased mortality from lung cancer and bronchiectasis in young adults after exposure to arsenic in utero and in early childhood. Environ Health Perspect 2006; 114: 1293-1296.

21 Karnani NG, Reisfield GM, Wilson GR. Evaluation of chronic dyspnea. Am Fam Physician 2005; 71: 1529-1537.

22 Pratter MR, Curley FJ, Dubois J, et al. Cause and evaluation of chronic dyspnea in a pulmonary disease clinic. Arch Intern Med 1989; 149: 2277-2282.

23 Sutherland ER, Cherniak RM. Management of chronic obstructive pulmonary disease. $N$ Engl J Med 2004; 350: 2689-2697.

24 Chen Y, Ahsan H. Cancer burden from arsenic in drinking water in Bangladesh. Am J Public Health 2004; 94: 741-743.

25 Chen CL, Chiou HY, Ling LI, et al. Ingested arsenic, characteristics of well water consumption and risk of different histological types of lung cancer in northeastern Taiwan. Environ Res 2010; 110: 455-462.

26 Nemery B. Metal toxicity and the respiratory tract. Eur Respir J 1990; 3: 202-219.

$27 \mathrm{Wu} \mathrm{MM}$, Kuo TL, Hwang $\mathrm{YH}$, et al. Dose-response relation between arsenic concentration in well water and mortality from cancers and vascular disease. Am J Epidemiol 1989; 130: 1123-1132.

28 Chen CJ, Chiou HY, Chiang MH, et al. Dose-response relationship between ischemic heart disease mortality and long-term arsenic exposure. Arterioscler Thromb Vasc Biol 1996; 16: 504-510.

29 Yuan Y, Marshall G, Ferreccio C, et al. Acute myocardial infarction mortality in comparison with lung and bladder cancer mortality in arsenic-exposed region II of Chile from 1950 to 2000. Am J Epidemiol 2007; 166: 1381-1391.

30 Zierold KM, Knobeloch L, Anderson H. Prevalence of chronic diseases in adults exposed to arsenic-contaminated drinking water. Am J Public Health 2004; 94: 1936-1937.
31 Medrano MA, Boix R, Pastor-Barriuso R, et al. Arsenic in public water supplies and cardiovascular mortality in Spain. Environ Res 2010; 110: 448-454.

32 Peto R, Lopez AD, Boreham J, et al. Mortality from smoking worldwide. Br Med Bull 1996; 52: 12-21.

33 Safwenberg U, Terent A, Lind L. Differences in long-term mortality for different emergency department presenting complaints. Acad Emerg Med 2008; 15: 9-16.

34 Abidov A, Rozanski A, Hachamovitch R, et al. Prognostic significance of dyspnea in patients referred for cardiac stress testing. N Engl J Med 2005; 353: 1889-1898.

35 Vestbo J, Knudsen KM, Rasmussen FV. Should we continue using questionnaires on breathlessness in epidemiologic surveys? Am Rev Respir Dis 1988; 137: 1114-1118.

36 Sorlie PD, Kannel WB, O'Connor G. Mortality associated with respiratory function and symptoms in advanced age: the Framingham study. Am Rev Respir Dis 1989; 140: 379-384.

37 Chen Y, van Geen A, Graziano JH, et al. Reduction in urinary arsenic levels in response to arsenic mitigation efforts in Araihazar, Bangladesh. Environ Health Perspect 2007; 115: 917-923.

38 Ahsan H, Chen Y, Parvez F, et al. Arsenic exposure from drinking water and risk of premalignant skin lesions in Bangladesh: baseline results from the health effects of arsenic longitudinal study. Am J Epidemiol 2006; 163: 1138-1148.

39 Haque R, Guha Mazumder DN, Samanta S, et al. Arsenic in drinking water and skin lesions: dose-response data from West Bengal, India. Epidemiology 2003; 14: 174-182.

40 Argos M, Kalra T, Rathouz PJ, et al. Arsenic exposure from drinking water, and all-cause and chronic disease mortalities in Bangladesh (HEALS): a prospective study. Lancet 2010; 376: 252-258. 